\title{
Enhancing pro-public-good professionalism in technical studies
}

\author{
Alejandra Boni Aristizábal y Carola Calabuig Tormo
}

Prefinal version of a paper which was published on line in July 2015 in The International Journal of Higher Education Research.

\begin{abstract}
In a university environment dominated by a traditional way of understanding knowledge, we argue that it is possible and necessary to foster capabilities among engineering students. Capabilities are understood as reasoned and substantive freedoms to lead the kind of life that people value, within a framework of respect for the core values of human development. In this sense, enhancing capabilities means fostering pro-public-good professionalism.

With insight from an interview study conducted at the Universitat Politécnica de Valéncia, in Spain, we will argue how formal and informal spaces have the potential to foster capabilities such participation, commitment, empathy, intercultural respect, critical thinking and selfreflexivity. These kinds of learning could be understood as a mixture of Procedural Know-how and Personal know how (Muller in this issue); as we will discuss in the last part of this paper, this kind of knowledge is difficult to assimilate within the framework of the terminology of skills and competences. Some recommendations for a capability oriented curriculum are presented in the final section.
\end{abstract}

\section{Keywords}

Capabilities, engineering studies, student associations, development education, formal and informal learning 


\section{Introduction}

Walker (think piece, in this issue) poses interesting questions on the role of science, technology, engineering and mathematics (STEM) in higher education. She argues: "How does higher education and STEM contribute to building a decent society which values creating capabilities for all its citizens and not just those who have the privilege of a STEM university degree [...] and how do science and engineering graduates use their knowledge, skills and effective power as professionals to make good lives for themselves while also contributing to sustainable human development as a public good?".

The links between STEM and, particularly, engineering education - the main field of our study and the public good is a challenging area. In the United States, Sheppard et al. (2009) highlighted, in their analysis of eleven mechanical and electrical engineering programmes, that "students have few opportunities to explore the implications of being a professional in society" (Sheppard et al., 2009: xxii). Even in the field of engineering ethics - by nature connected with the idea of public good - there has been more interest towards protecting the public from professional misconduct by engineers and from the harmful effects of technology than some aspects of engineering professionalism, such awareness of the social context of technology, respect for nature and commitment to the public good (Harris, 2008:153).

This paper aims to explore the relationships between engineering education and the public good by using the capabilities approach perspective; with insights from an interview study conducted at the Universitat Politécnica de Valencia (Technical University of Valencia, thereafter UPV), we will explore the links between higher education and capabilities. In this sense, the paper follows on from previous work by various authors (Walker, 2006; Walker and Mc Lean, 2013; Boni and Walker, 2013, Crosbie, 2013; Spreafico, 2013), and adds the specificity of the engineering field, which is a less explored area. However, we must acknowledge that other authors, outside the capabilities approach community, have reflected on the importance of the social aspects of sustainable development for engineers' practice (Cruickshank and Fenner, 2007); also, Baille and Levine (2013), make the case for a new paradigm of engineering ethics, which is based on justice principles (i.e. Rawls, 1971; Sen, 1999) and focused on balancing diversity and equity and participatory engagement in engineering. As we will see in this paper, these perspectives on engineering practice are strongly connected with our idea of pro-public-good professionalism based on the capabilities approach.

The structure of this paper is as follows: firstly, in the next section, we will give an overview of the main elements of the capability approach; secondly, we will describe the two learning spaces examined and we will explain the main characteristics of our interview study; thirdly, we will discuss some of the results; fourthly, we will engage in the discussion of what kind of knowledge has been created and how the mainstream language of skills and competences does not accurately capture the idea of capabilities, and its transformative potential. To conclude, we will present some ideas for a capability-oriented curriculum.

\section{Key elements of the capabilities approach}

Capabilities are defined, by Sen (1999:87), as 'the substantive freedoms to lead the kind of life that people value'. Functionings are the activities that people perform and that are valued by them. The approach emphasises the importance of assessment by the people, referring to capabilities as well as functionings. It is important to understand the idea of capabilities as freedoms or opportunities. They cannot be desires, but must be something that can be put into 
practice. They include both material things (the capability would be being nourished and the functioning would be eating) and people's states (the capacity would be having political convictions and the functioning would be starting a hunger strike). Sen reminds us that the most important thing is that people have the freedoms or valuable opportunities (capabilities) to lead the kind of lives they want to lead, to do what they want to do and be the person they want to be. Once they actually have these substantive opportunities, they may choose to implement the options that they most value.

Another seminal author focusing on the capability approach is Martha Nussbaum who presents a list of ten central capabilities for the functioning of human beings (Nussbaum, 2000); these are the fundamental requirements for a decent life, which together represent a minimal agreement on social justice. A society that does not guarantee these capabilities to all its citizens, at an appropriate level, cannot be considered a just society, whatever its level of affluence (Nussbaum, 2000). Nussbaum's list has been criticised and debated due to its universalistic, non context-sensitive character; however, it has also been shared because it represents a global, internationalist and social justice-oriented position, given that the public policies being designed should serve to increase the capabilities of citizens.

If the capability is the freedom of opportunity, then agency is the freedom of process. Agency refers to the ability of the individual to pursue and achieve the objectives they value. A person with agency is an agent who is "someone who acts and makes change happen" Sen (1999). Otherwise a person with agency is someone oppressed, forced or passive. According to Alkire and Deneulin (2010: 37) agency is characterised by: 1) having to do with the goals that people value; 2) involving effective power and control, not only individual agency but also what a person can perform as a member of a group, community or political community; 3) being able to pursue well-being or other objectives that are somehow reasonable (humiliating others cannot be understood as an agency); 4) including the responsibility of the agent to want to achieve those goals.

Another key element of the capabilities approach is its explicit reference to development as the promotion of human values. Therefore, the development of society is a normative concept that differs from economic growth or social change, whose content should be explicitly evaluated. The standard definition of the dimensions of human development by the United Nations Programme for Development has covered: 1) empowerment, understood as the expansion of people's capabilities (real opportunities to achieve valuable ends) and the expansion of valuable functionings (valuable purposes achieved), and participation, 2) the equitable distribution of basic skills, 3) sustainability and 4) the safety of the people to enjoy their opportunities and achievements (Boni and Gasper, 2012). Furthermore, Penz et al. (2010), in reviewing the evolution of thinking about human development, identified six groups of values that have formed the basis for discussions on human development over the past fifty years: 1) welfare and human security, 2) equity, 3) participation and empowerment, 4) human rights, 5) cultural freedom, and 6) environmental sustainability.

Taking into account the above elements, and for the purpose of this research, we can define public good as the expansion of people's capabilities, functionings and agency within a framework of respect for the core values of human development.

\section{The interview study}

With the aim of exploring the kind of capabilities that can be enhanced in a technical environment, we conducted an interview study at UPV. Its character is mainly exploratory, due 
its sample limitation; however, we consider that could be useful as a preliminary reflection in order to explore the differences between formal and informal spaces as learning environments to boost capabilities. In the following section we will explain some characteristics of this two learning environments; after it, we will give explicit details of the research design.

\section{Mueve and the electives at UPV}

Mueve was a university group, founded in 2004 by ten students from the School of Industrial Engineering (ETSII) at UPV. In one of the first meetings, the founders defined the group philosophy as follows: "The Mueve group is part of the ETSII Student Union and aims to promote analytical awareness and active participation among students to achieve a more supportive, ecological, ethical and plural university".

Some of its objectives were to promote critical involvement and active participation among students. To this end, the group intended to carry out direct actions and campaigns inspired by solidarity, diversity, ethical and ecological principles. These campaigns had a mainly didactic purpose, promoting the development of critical awareness among technical students. The goal was to make the students aware of their future social relevance in achieving sustainable development that has a regard for human rights and the natural environment.

Mueve had different working groups, which were coordinated through monthly assemblies. Examples of these groups were the Ecology Group, which aimed to promote cycling as the main way of urban transport among students, and the For Peace and against Military Research Group, which campaigned to make students aware that military research was taking place at the university. The latter organised various 'Peace Days' and collected many research demurrer statements, where researchers committed to avoiding involvement in research with military objectives. There was also a Fair Trade Group, which tried to raise awareness about responsible consumption and the promotion of fair trade. They promoted the introduction of the first fair trade coffee machines at the university and also offered 'tasting days' and fair trade exhibitions. Finally, there was the Culture and Ethics Group, which organised themed film seasons and exhibitions to raise the critical awareness of students. All these activities were carried out during five years by a number of students that varied from year to year. A core group of 10-15 students was the more active, while other students joined them occasionally.

Mueve stopped active campaigning in 2009 but it left behind a long-term legacy. Firstly it was an innovative participation proposal that inspired other student groups in other universities in Valencia. Some of these have taken over some of the projects started by Mueve. Secondly, it played the role of a citizen's school for most of the thirty student members, who are still working together at present, either individually or collectively, at home or at work, for a more supportive, ecological, ethical and diverse society. Thirdly, former Mueve members continue to promote the group's aims and principles. Some are currently working at the university as teachers or researchers. Others work for private companies, mainly involved with renewable energies or mobility.

The second case deals with the two elective courses, Introduction to Development Aid and Development Aid Projects. These were started in the mid 90s by the NGO Ingeniería Sin Fronteras (Engineers without Borders) and proposed the integration of development education into technical studies as a way of contributing to human development and promoting long-term structural changes in the higher education system. This strategic approach to human development was intended to provide the students with a serious and objective knowledge of 
the Global South, including a vision of the interdependent problems faced by humanity, whilst simultaneously raising awareness of the consequences of our actions and attitudes, as well as encouraging active social involvement and volunteering.

In the following years, the NGO's volunteers were replaced by a group of teachers specialised in the area of development (most of them volunteers of Engineers Without Borders) and the two courses came to be implemented in several of UPV's schools including Industrial Engineering, Agronomic Engineering, Civil Engineering, Computer Science and Telecommunications Engineering as well as in undergraduate programmes in Business Management, Life Sciences and Fine Arts. Since they were first introduced, up until 2011, more than 3,000 students took these elective courses at the UPV (Boni et al., 2012).

The goals and contents of the curriculum and the pedagogical approach followed the development education paradigm described by Cameron and Fairbrass (2004), which seeks the empowerment of people through teaching-learning processes. The classes were divided into two main parts. Firstly, lectures were complemented by practical sessions, during which the teacher introduced activities such as case studies, moral dilemmas, role-play, video-forums, conceptual mapping, project drafts and small or whole group discussions which were designed to articulate and encourage debate about the theoretical content of the subjects. Secondly, during the seminars, each group focused on specific issues in greater detail, which were then presented and discussed with the rest of the class. Participation became a key feature of the teaching-learning process and teachers from different parts of the Global South and NGO members were actively involved in the classroom by talking about their experiences.

In addition, students could engage in short-term internships in NGOs in Valencia and the surrounding area. Between 1995 and 2008, 189 students had practical experience in 16 NGOs situated in the city of Valencia (Calabuig \& Gómez-Torres, 2008). They contributed to each organisation in different ways by doing various kinds of tasks in relation to social issues. The majority of the students considered the experience to be extremely positive, as they were able to become acquainted with the various problems encountered in each context and became aware of their ability to overcome their prejudices towards people such as gypsies, migrants and former prison inmates (Boni and Taylor, 2011).

Unfortunately, since the beginning of 2010, when the landscape of Spanish Degree courses changed due to the Bologna Process (the European Higher Education Area), these two subjects have gradually disappeared. The free election category, which was intended to be a complementary course alongside the traditional engineering curriculum, was eliminated. Thus, contents related to ethics, development, science and technology studies were removed from the curriculum, despite efforts made by teachers, the previously mentioned Mueve group, other university associations and former students of the two subjects. In a handful of cases, some universities have, in 2013, introduced a subject related to professional ethics in the new degrees, but global issues are not always considered.

\section{The research design}

In this exploratory study conducted in 2010, we interviewed six women and six men, aged from twenty-four to thirty years old, all of whom with a technical background in engineering from the UPV. The interviewees were selected as follows: three of them had both taken the elective subjects and participated in Mueve; another three had only participated in Mueve; three more had only taken the elective subjects and did not have any experience volunteering for a social group; and finally, the last three had taken the elective subjects and had been involved in social organisations in order to acquire practical experience. All of them gave their consent to participate in this study and their names have been changed to respect their anonymity. 
We did not look for generalisations; on the contrary, we considered that our qualitative methodology allowed us to deepen on the students' experiences and reflections. Nevertheless, we acknowledge the limitations of our study, due to its limited sample, specially with regard to the electives.

The questions and the structure of the interviews were inspired by literature on the capabilities approach. The most influential insights come from Nussbam (2006) and her proposal of the three capabilities for democratic citizenship, and the list of eight capabilities for higher education proposed by Walker (2006). Nussbaum (2006) refers to, firstly, "the capability of critical examination or critical thinking which "requires developing the capability to reason logically, to test what one reads or says for consistency of reasoning, correctness of fact, and accuracy of judgement (2006, p. 388)"; secondly, the cosmopolitan capability focuses on "understanding the differences that make understanding difficult between groups and nations and the shared human needs and interests that make understanding essential, if common problems are to be solved, which includes the related task of understanding differences internal to one's own nation" (2006, p. 390) and, finally, narrative imagination, is concerned "with the ability to think what it might be like to be in the shoes of a person different from oneself, to be an intelligent reader of that person's story, and to understand the emotions, wishes and desires that someone so placed might have" (2006, pp. 390-391). Walker's contribution (2006 and think piece in this issue) presents a list of the following 8 capabilities: 1) Practical reason, 2) Educational resilience, 3) Knowledge and imagination, 4) Learning disposition, 5) Social relations and social networks, 6) Respect, dignity and recognition, 7) Emotional integrity and emotions, 8) Bodily integrity.

Inspired by the two contributions which have proven to be very helpful in assessing learning outcomes in higher education studies (Boni et al., 2012; Sastre et al., 2012; Crosbie, 2013), we drew up our own list of the following capabilities: 1) Critical thinking - the ability to reason in a logical and argumentative manner; 2) Empathy - to appreciate what it must be like to be in somebody else's shoes; 3) Participation - at local and global levels; 4) Social commitment; 5) Coexistence and intercultural respect; 6) Reflexivity; 7) Curiosity.

The first two were both in Nussbaum's and Walker's lists; participation at local and global levels is connected with the cosmopolitan capability and the idea of agency, one of the core concepts of the capability approach; social commitment, coexistence and intercultural respect, reflexivity and curiosity are described in Walker's list.

However, to allow a more open dialogue between the interviewer and the interviewee, the first part of the interview was more general and aimed to explore what the students valued most from their experience in Mueve or the elective courses. The interviewees were then asked to organise and rank these capabilities according to two different criteria: (i) whether the elective courses or Mueve had contributed to the development of these capabilities; and (ii) which of these they felt were most relevant to them. The interviews typically ended by asking the interviewee to add any other capabilities or topics they considered interesting.

All the interviews were full transcribed and several categories were established following 1) the different capabilities contained in the list, 2) other capabilities suggested by the interviewees and 3) other remarks not specifically related with capabilities but with aspect of their learning processes. Since our study was inspired by the capability approach framework, it is possible that the main focus on capabilities (and the use of rankings) may have obscured other learning outcomes. We are aware of it, but, as mentioned before, our aim was to gain insights from this study to exemplify a discussion on the links between capabilities and higher education. 
Furthermore, to avoid bias in this study, since the authors of this paper were teachers of the electives, results were discussed with two members of Mueve (not interviewed), another teacher of the electives and a teacher who was not part of them. Two sessions were conducted, in which preliminary results were discussed and refined. Additionally, the results pertaining to the electives were confronted with another study conducted between 2005 and 2007 (Boni et al, 2012) where, using discourse analysis, we carried out a thorough analysis of 80 questionnaires written by the students attending the subject 'Introduction to Development Aid' over a period of two years (2005/06 and 2006/07). This study was based in the same theoretical framework: Nussbaum's three capabilities for a democratic citizenship. Although methods used in both studies were different, the findings of the discourse analysis' study were similar to the evidences of our interview study. Thus, even if partially, the weakest part of our study to its sample limitation, has been somehow strengthened.

\section{Pro-public-good professionalism among UPV students}

The interview study highlighted several key issues relating to the development of capabilities in the different spaces at the UPV. We will start with the kind of capabilities the students identified. Firstly, three of the interviewees that had participated in Mueve and taken the electives stated clearly: the elective courses had provided knowledge, including a theoretical basis, that had made them more sensitive to global issues, whereas Mueve had provided a positive and realistic dimension that had opened up the possibility of making changes. Antonio summed it up as follows:

The electives have given me a framework for interpreting the world, showing me the structural motives. They were also useful in structuring what I already knew. They helped me to reflect and think about social justice ... Mueve had an inspirational spirit. It helped me to generate commitment and understand the changes ... The subjects and Mueve complemented each other. Mueve was more locally orientated while the subjects had a global orientation. But we could say that they followed a logical evolution from local motives to global ones and from these to global justice. Both of them have helped me to open my mind and open up new horizons.

The interviewees only involved in Mueve explained how the group had helped them to acquire the abilities to:

- work properly in groups, organise themselves in groups and produce collective work;

- become aware, discover the ability to do things and be able to change;

- understand changes and generate commitment;

- $\quad$ persevere and fulfil obligations;

- promote different perspectives on life;

- develop a range of problem-solving abilities and deal with stress; and

- organise and manage ideas.

Luca went further and credited Mueve with developing a sense of intercultural citizenship. He explained how it had helped him to "build myself as a person, as a professional and as a citizen, 
to claim my rights and spaces [but] also to understand my obligations." He then went on to talk about sharing this with others, including group members outside Valencia, "so talking to somebody who is in a different part of the world becomes something usual [and] natural."

An exception was Aurora who seemed worried, and even somewhat obsessed, with the issue of equal rights for all and outraged by inequality and the lack of respect for minorities. However, she then defined herself as a conformist because she believed that "Things cannot be changed. It is very difficult to face up to and try to change things and overcome the general inertia." However, she also recognised that her involvement in Mueve changed her perspective by showing her that things were gradually changing.

The students who had taken only the electives highlighted a different set of abilities, which were not acquired through life or group experiences but are, nevertheless, valuable:

- knowledge acquisition to understand the complexity of development;

- the development of critical thinking;

- the ability to participate actively and express personal opinions;

- the ability to listen, to be tolerant of different ideas and to be able to understand the reasons behind others' behaviour; and

- awareness of the need to consider context before taking action, particularly when facing situations that involve international cooperation.

These are more reflexive characteristics that are typical of a formal learning context. We had expected the students who had been involved in practical voluntary work to identify at least some aspects related to them - aspects similar to those identified by the Mueve participants. However, the responses of these students were almost the same as those of the students who had not taken part in voluntary projects. We will discuss this point later.

With regard to the capability list provided during the interview, for those who had been involved with Mueve, the most important capabilities selected were: (i) participation; (ii) commitment; (iii) empathy; and (iv) coexistence and intercultural respect. Maria summed up the importance of Mueve as she saw it, describing it as "a participation forum, a space to seek agreement and ideas, to produce them, to get answers, positive or not. It was never an introspective or philosophical activity." In considering commitment, she emphasised the group's commitment to ideas. However, she also explained that if she were to fail in meeting a commitment, she would not just be letting herself down, but the whole group. This concern with action and with solidarity framed her reflections on the importance of empathy and coexistence.

For those who had taken the elective subjects, the most important capability selected was that of critical thinking. Luca explained how:

Nowadays, when I read news [that] tries to give an excessively nice picture of certain issues, I know it is not like that. Of course, in this respect critical thinking has changed us, as it has provided us with information that allows us to say: 'No, it's not like that' ... We did not do that before [taking the elective subjects].

The other capabilities were also valued positively, but without the same levels of consensus. 


\section{Differences and similarities between the two learning spaces}

Our study highlights two initiatives to introduce UPV students to the wider world in order to develop a public-good professional. However, our research indicates that the participants believed they each led to the development of different capabilities. This is not surprising, as one was institutionally led and the other student led. In this context, the institutionally led elective subjects can be broadly characterised as facilitating reflection leading to (possible) action, whilst the student-led Mueve can be seen as encouraging action leading to reflection. However, there was some crossover between them: the elective courses encouraged engagement with local and global groups; Mueve sought to influence some teaching (e.g. by persuading the university to do away with its military connections) and some former participants have gone on to teach at the university.

Starting from the three capabilities highlighted by Nussbaum (2006), we could argue that in the elective courses there is a potential to foster critical thinking, while in Mueve it is possible to find more narrative imagination, especially the cosmopolitan capability.

Harrison and Peacock (2010) found that what they term 'informed cosmopolitanism' (the opposite of the 'passive xenophobia' they describe) was more often found in students on creative arts courses. However, the elective courses offered at UPV could indicate that this can be encouraged in engineering spaces. This argument is consistent with one study conducted in USA where Moskal et al. (2008) showed the potential of the Humanitarian Engineering programme of the Colorado School of Mines in developing a sense of cosmopolitanism. Also, the Mueve experience shows similar results to those developed in the US, based on the participation of engineering students in NGOs. As Passino states: "experience shows that these activities provide significant motivation, knowledge of how to build on idealism, and a strengthened spirit of volunteerism in new engineering graduates" (Passino, 2009:578).

Although our study suggests that those taking these electives did not explicitly recognise their cosmopolitan capability (as suggested by Nussbaum) the students were encouraged to think critically about global issues; because these problems were located in the curricula, they were able to articulate their subject with this 'informed cosmopolitanism' rather than simply and passively acquiring knowledge. This suggests that the electives had the potential of creating globally-oriented spaces in which to foster the critical reflection that is a central element of wellbeing in general (Nussbaum, 2000) and higher education in particular (Walker, 2006).

The students valued the reflective spaces offered by the elective courses, but there is a sense that they wanted to put their learning into practice. Mueve enabled direct and immediate engagement with a wider community, even though that engagement took place locally. Osler notes that it is 'within the local community that most individuals first engage as citizens' (2011, p. 19). Mueve enabled an understanding of citizenship rooted at the local level that could (and typically did) encourage that understanding to flourish at the global level. It offered practical activism that cannot easily be incorporated into the electives - particularly if the practical activities of the electives are to be relevant to the subjects.

Whether or not practical activities are aligned to academic subjects, local engagement is important to the development of the cosmopolitan capability. After all, unless we choose to leave them, it is in our local communities that we are able to show our commitment to citizenship. Yet, as Rizvi explains, the global citizen does not stop thinking at the local level:

"The immediate issues we have to deal with are invariably local. If this is so, then, I believe that our approach to teaching about global connectivity should begin with the local, but must move quickly to address issues of how our local communities are 
becoming socially transformed through their links with communities around the world, and with what consequences" (Rizvi, 2009, p. 263).

Community engagement at the local level helps shape the reflective understanding that allows us to think of ourselves as global citizens - whether we are in Spain, South Africa or Ecuador. Wherever we are, it is part of the wider world and it is up to us to recognise that. We may be situated locally, but we can define ourselves globally.

Finally, we can argue that we can find in Mueve traces of strong agency. From our perspective, two elements of agency are especially important to enhance capabilities and pursue human development goals: reflexivity and responsibility (Boni and Walker, 2013). On one side, critical reflexivity and Freire's (1978) conscious awareness of being an agent become relevant in the framework of collective action. In this regard, deliberation and reflective dialogue become core elements for developing agency because "not just any behaviour that an agent "emits" is an agency achievement' (Crocker, 2008: 11). There must be a certain reflection and conscious deliberation of the reasons and values upholding agency: "what is needed is not merely freedom and power to act, but also freedom and power to question and reassess the prevailing norms and values' (Dreze and Sen, 2002: 258). The second element is the responsibility towards others. Ballet et al. (2007) propose to broaden Sen's concept of agency by considering responsibility as a constitutive characteristic of the person at the same level as freedom. This has important consequences as it generates a distinction between weak and strong agency. While weak agency would refer solely to developing individual goals and capabilities, strong agency would include the exercise of responsibility towards others' capabilities and society as a whole. Agency becomes strong agency when it aims to expand the freedom of others within a network of social interactions where commitment and responsibility take place (Peris et al., 2012).

Thus, according to this definition, Mueve proved to have the potential to enhance strong agency, whilst the electives focused more on the reflective component of the agency that is an essential step towards strong agency. When we designed the electives, the assumption was that the voluntary placements in local NGDOs could have been spaces to foster strong agency. However, our findings show that this was not the case. Further research needs to be made to properly analyse the potential of voluntary placements to foster strong agency among students.

\section{What kind of knowledge is needed for pro-public-good professionalism in engineering studies?}

Muller (think piece in this issue) argues that STEM disciplines could be characterised by two different kinds of scenarios that are responses to the challenges of knowledge specialization and differentiatedness: Scenario 1 is dominated by a specialisation of knowledge, driven equally by the production of new knowledge, new technological challenges, and new elaborations in the division of labour. This Scenario has most recently taken refuge in technological/technocratic solutions to educational problems, taking for granted the fixity of the knowledge horizon and locate the problem 'out there' with the educational participants, or the technologies that mediate them. Scenario 2 is based on the differentiatedness of knowledge, different disciplines with various epistemic and social properties. According to this perspective, the teacher and the learner, the two founts of activity, became the focus of the scholarly academic development gaze. However, in STEM disciplines, this Scenario 2 has tended to get stuck with an oversocialised and undifferentiated conception of knowledge as activity.

Muller (think piece in this issue) also argues that a Scenario 3 is possible, a space that explores what it means to move the debate forward by combining the positive features of Scenarios 1 and 2 whilst trying to avoid their worst features. 
We argue that engineering studies in our University are, nowadays, clearly dominated by a Scenario 1 kind of knowledge. The elimination of free electives of a more interdisciplinary character is one of the symptoms, but not the only one. In a case study of how a new degree on Engineering Design was implemented at the UPV, we found that essential questions about the teaching and learning processes were not on the agenda of those who had defined the new degree. Educational goals, student profiles, contents, learning methodologies and assessment system were not discussed properly during its design process, and even employability perspectives had not been considered. In the end, the new curriculum focused only on instrumental skills and was designed by the most powerful departments in the School of Engineering Design (Boni et al., 2009). Thus, this is not only a question of what kind of knowledge is involved, but also a matter related to educational arrangements and institutional culture, all of which are shaped by power relations.

It is beyond the scope of this paper to discuss in detail the relation between knowledge production and power relations inside higher education institutions, but the lesson learned from the study is clear: to promote change on the kind of knowledge and pedagogies to be taught in engineering studies (the Scenario 2 or 3 possibilities) is something that has to be worked at in a very careful and inclusive way, taking into account all the different actors involved and based on open discussions and clear agreements. Capabilities and human development principles could be a proper guide to this, as we will see in the next section.

Coming back to the argument set out in the introduction to this paper, if we look at engineering professionals not only as drivers of economic efficiency but also as enlightened, responsible and constructively critical citizens (Walker, think piece, in this issue) the kind of knowledge taught in engineering studies should be more similar to Scenario 3. It needs to take into account the instrumental perspective, but it also has to incorporate contents, promote skills, abilities and even attitudes that equip students with the kind of capabilities as those highlighted by our interviewees: to be a critical thinker, to be a person that understands and makes change happen, that generates social commitment and fulfils obligations, that understands and respects different perspectives on life, that is able to work in teams and manage them, etc.

Following Muller's arguments (think piece in this issue) these kind of capabilities are more related with procedural and personal know-how that with inferential know-how. As we have analyzed in this paper, the capabilities and the strong agency promoted in Mueve are based on experiential knowledge developed in the "real world" which is essential for procedural and personal know-how. In the electives, presence of that kind of knowledge is less evident, although students remark the importance of critical thinking and reflexivity, which are the first step to develop procedural know-how. If we follow Muller's definition of it (think piece, in this issue), both elements are crucial to find out new things, find out what warrants and form new judgments that lead to solutions that work in the world.

\section{Conclusions. Recommendations for a capability-oriented curriculum}

Thinking about the possible ways forward to promote procedural and personal knowledge - with a capabilities outlook - in STEM's studies, we suggest four main practical recommendations.

The one most directly connected with our analysis is the importance of promoting experiential learning spaces; this could be a students' association like Mueve or temporary internships in local or global contexts. In the end, they have proven to be appropriate spaces to promote a powerful understanding of pro-public-good professionalism. 
Secondly, we consider that is important to accompany these experiential moments with selfreflection and critical-thinking processes that help understand action from a pro-public-good perspective; or, in the language of capabilities, to cultivate strong agency. To activate these reflective and learning processes university teachers should act more as facilitators than transmitters of knowledge.

Our third recommendation is related to the limitation of the language of skills and competences (also highlighted by Muller, think piece, in this issue). As discussed elsewhere (Lozano et al., 2012) competences are functional, demand-oriented and, in present times, clearly related to the employability discourse. On the contrary, capabilities are ethical and normative and are guided by the exercise of individual freedom to choose and develop the desired lifestyle and, therefore, the values individuals consider to be desirable and appropriate. If we consider the role of agency, whilst the competencies approach focuses on enabling actions to solve problems that are set externally, in the capabilities approach the notion of agency is essential. The implications for higher education are significant, since the proper goal here is not to align education with 'what society is', but to orient it towards 'what society should be'. In this regard, the consideration of general principles such as equity, freedom and participation is central. Thus, the capabilities approach could critically scrutinise the language of competences and could be useful to substitute or, at least, complement the mainstream competences approach.

Finally, we conclude with a contribution to the process of defining curricula content. In this respect, the capabilities approach suggests that it is important to develop an inclusive deliberative process in which all voices (students, teachers, university management and staff, politicians, and society at large) can be heard under the principles of equity and diversity (Roth 2003, Hinchliffe 2009, Unterhalter 2009). Furthermore, implementation of the curriculum should not be technocratic, with a list of closed, predefined competencies for incorporation in all degree course syllabuses. Thus, general proposals should be reinterpreted according to the needs, concerns and characteristics of the particular context in which the education takes place. The capabilities approach requires us to go beyond employability (without undervaluing it!) as the goal of higher education; it proposes valuing graduates' involvement in social and political initiatives, and their personal development. From this perspective, the capabilities approach could contribute to what was stated at the beginning of Bologna Process in the Leuven Communiqué (adopted in April 2009 by the Conference of European Ministers Responsible for Higher Education): "Student-centred learning requires empowering individual learners, new approaches to teaching and learning, effective support and guidance structures and a curriculum focused more clearly on the learner in all three cycles" (Bologna Process 2009: 3).

\section{References}

Alkire, S., Deneulin, S., (2010). The human development and capability approach. In: S. Deneulin and L. Shahani, eds. 2010. An introduction to the human development and capability approach. London: Earthscan, pp. 22-49.

Baillie, C. and Levine, M. (2013), Engineering ethics from a justice perspective: a critical repositioning of what it means to be an engineer, International Journal of Engineering, Social Justice and Peace, 2,1, pp. 10-20

Ballet, J., Dubois, J.L. and Mahieu, F., (2007). Responsibility for Each Other's Freedom: Agency as the Source of Collective Capability. Journal of Human Development and Capabilities: A Multi-Disciplinary Journal for People-Centered Development, 8, pp. 185-201. 
BOLOGNA PROCESS, (2009), The Bologna Process 2020 - The European Higher Education Area in the new decade, Communiqué of the Conference of European Ministers Responsible for Higher Education, Leuven and Louvain-la-Neuve, 28-29 April 2009 avalaible at http://www.ond.vlaanderen.be/hogeronderwijs/bologna/conference/documents/Leuven_Louvainla-Neuve_Communiqu\%C3\%A9_April_2009.pdf [retrieved 15h October 2014].

Boni, A. , Peris, J, López, E. and A. Hueso, (2009). Scrutinising the Process of Adaptation to the European Higher Education Area in a Spanish University Degree Using Power Analysis, Power and Education, 1,3, pp. 319-332

Boni, A. and Taylor, P. (2011), Higher education institutions as cosmopolitan spaces for transformative development: re-imagining learning through teaching, Occasional Paper, 23, Democratising knowledge for global development: the role of European higher education institutions, Arts, Halvorsen and Taylor (ed.) European Association for International Education: $69-81$

Boni, A. and Gasper, D. (2012), Rethinking the quality of universities - How can human development thinking contribute? Journal of Human Development and Capabilities, 13,3: 451470.

Boni, A., MacDonald, P. Peris, J. (2012), Cultivating engineers' humanity: Fostering cosmopolitanism in a Technical University, International Journal of Educational Development, $32,179-186$.

Boni, A. and Walker, M. (Eds) (2013), Universities and Human Development. A New Imaginary for the University of the XXI Century, London: Routledge.

Cameron, J. \& Fairbrass, S. (2004), From Development Awareness to Enabling Effective Support: the changing profile of development education in England, Journal of International Development, 16[5], 729-740.

Crocker, D., (2008). Sen's concepts of agency. In: Human Development and Capability Association, 8th International Conference of the Human Development and Capability Association. India, New Delhi, 10-13 September 2008. New Delhi: HDCA

Crosbie, V. (2013) "Capabilities and a pedagogy for global identities" in Boni, A. and Walker, M. (eds) Universities and Human Development. A New Imaginary for the University of the XXI Century, London: Routledge. pp. 178-191.

Cruickshank, H. \& Fenner, R.A. (2007) The Evolving Role of Engineers: toward sustainable development of the built environment, Journal of International Development, 19[1], 111-121.

Dreze, J. and Sen, A., (2002). India: Development and participation. Oxford: Oxford University Press.

Freire, P. (1978), Pedagogía del oprimido, Madrid: Siglo XXI.

Harris, C. Jr. (2008), The Good Engineer: Giving Virtue its Due in Engineering Ethics, Sci Eng Ethics 14:153-1643

Harrison, N. \& Peacock, N. (2010) Cultural Distance, Mindfulness and Passive Xenophobia: using integrated threat theory to explore home higher education students' perspectives on 'internationalisation at home', British Educational Research Journal, 36(6), 877-902. 
Hinchliffe, G. (2009), Capability and Deliberation, Studies in philosophy and education, 28, pp.403-413

Lozano, J.F., Boni, A., Peris, J. and Hueso, A. (2012). Competencies in Higher Education: A Critical Analysis from the Capabilities Approach. Journal of Philosophy of Education, 46, 1, 132147.

Moskal, B. M., Skokan, C., Munoz, D., \& Gosink, J. (2008). Humanitarian Engineering: Global Impacts and sustainability of a Curricular Effort. International Journal of Engineering Education, 24(1), $162-174$.

Nussbaum, M., (2000). Women and human development: The capabilities approach. Cambridge: Cambridge University Press.

Nussbaum, M., (2006). Education and democratic citizenship: capabilities and quality education. Journal of Human Development, 7 (3), pp. 385-395.

Osler, A. (2011), Teacher Interpretations of Citizenship Education: national identity, cosmopolitan ideals, and political realities, Journal of Curriculum Studies, 43(1), 1-24.

Passino, K. M. (2009), Educating the Humanitarian Engineer. Science and Engineering Ethics, 2009(15), 577-600.

Penz, P., Drydyk, J. and Bose, P., (2010), Displacement by Development. Ethics, Rights and Responsibilities. Cambridge: Cambridge University Press.

Peris, J., Fariñas, S., López, E. and Boni, A. (2012), Expanding collective agency in rural Indigenous communities in Guatemala: a case for El Almanario approach, International Development Planning Review, 34 (1).

Rawls, J. (1971). A theory of justice, Cambridge, MA: Cambridge University Press.

Rizvi, F. (2009) Towards Cosmopolitan Learning, Discourse: Studies in the Cultural Politics of Education, 30(3), 253-268.

Roth, K. (2003), Freedom of Choice, Community and Deliberation, Journal of Philosophy of Education, 37.3, pp.393-413

Sastre, J.J., Boni, A., Fernández-Baldor, A. and M.LL. Gómez-Torres, (2012), Análisis del programa Meridies-Cooperación de la Universitat Politècnica de València desde el enfoque de capacidades, en Desafíos de los Estudios del Desarrollo: Actas del I Congreso Internacional de Estudios del Desarrollo, Dominguez, R. and S. Tezanos (eds.), Red Española de Estudios del Desarrollo (REEDES). Pp: 1991-2019

Sen, A., (1999). Development as Freedom. New York: Knopf.

Sheppard, S. D., Macatangay, K., Colby, A. and Sullivan, W.M., (2009), Educating Engineers. Designing for the future of the field. San Francisco: Jossey-Bass and The Carnegie Foundation.

Spreafico, A.M.C, (2013) Liberal arts education and the formation of valuable capabilities in Boni, A. and Walker, M. (Eds) Universities and Human Development. A New Imaginary for the University of the XXI Century, London: Routledge. 
Unterhalter, E., (2009) What is equality in education? Reflections from the capability approach, Studies on Philosophy and education, 28, pp.415-424

Walker, M., (2006), Higher education pedagogies. Berkshire and New York:Society for Research into Higher Education and Open University Press.

Walker, M. and McLean, M. (2013), The Global Engineer Professional Education, Capabilities and the Public Good, London: Routledge. 